\title{
Beyond Methodological Individualism and the Myth of the Entrepreneur: The Systemic Thinking Model of Entrepreneurship
}

\author{
Gaëlle Vallée-Tourangeau ( $g$ •vallee-tourangeau@kingston.ac.uk) \\ Department of Management, Kingston Hill, \\ Kingston-upon-Thames, KT2 7LB, UK \\ Frédéric Vallée-Tourangeau (f.vallee-tourangeau@kingston.ac.uk) \\ Department of Psychology, Penrhyn road, \\ Kingston-upon-Thames, KT1 2EE, UK
}

Entrepreneurship is an elusive concept. Derived from the French entreprendre, it means to undertake, to begin, to take on. Yet not all beginners are entrepreneurs. Entrepreneurs are also defined by their risk appetite and their hope for profit (English Oxford Living Dictionaries, n.d.). But these descriptives also seem to fail to account for the fascination that (successful) entrepreneurs seem to hold. Entrepreneurs, much like creators, inventors, or artists fascinate because of their ability to see what could be. To think of inspiring successful artists such as Picasso or successful entrepreneurs such as Steve Jobs, is to think of visionaries, people who had an extraordinary ability to use their imagination or wisdom to plan the future: unique individuals with formidable minds.

This is echoed in scholarly definitions of entrepreneurs as people who have an orientation toward seeing and acting upon opportunities (Krueger, 2005; Stevenson and Jarillo, 1990). This view of entrepreneurs presents entrepreneurship as an activity that is inherently cognitive, supported by mental processes such as perception, knowledge representation, decision-making, problem-solving, or learning. It seems natural, then, to adopt the classical information-processing (CIP) model of cognitive science as a framework for studying entrepreneurial cognition, and 
conceptualises entrepreneurship as a fundamentally cerebral, information-processing activity (see Figure 1).

\begin{tabular}{|c|c|c|c|c|c|c|}
\hline $\begin{array}{l}\text { Perceived } \\
\text { Opportunity }\end{array}$ & shapes & $\begin{array}{c}\text { Mental } \\
\text { Representation }\end{array}$ & affords & $\begin{array}{l}\text { Cognitive } \\
\text { Processing }\end{array}$ & shapes & $\begin{array}{l}\text { Enacted } \\
\text { Action }\end{array}$ \\
\hline
\end{tabular}

Figure 1. Classical Information Processing Model of Entrepreneurial Cognition

Yet, despite its intuitive appeal, the CIP model is not suited to account for human cognition in general, and entrepreneurial cognition in particular. To illustrate, consider the archetype metaphor of cognition, the Turing machine. In his famous essay, Alan Turing (1936) conceived a (human) mathematician as a computing machine that is composed of an initial state of mind, a set of computations that can be applied to manipulate information that is on his mind, and produce a new state of mind. The Turing machine metaphor or simply the "mind as machine" metaphor has had an enduring influence on modern conceptions of cognition (e.g., Fodor, 1981). To this day, mainstream cognitive psychologists view research in computational cognitive modelling as exploring the essence of cognition (Sun, 2008), independently of where such computations take place (be it in a human brain or, say, in a cognitive psychologist's computer).

Applied to entrepreneurial cognition, this metaphor implicitly assumes that the key to achieve a theoretical understanding of how entrepreneurs perceive opportunities, think and act upon them, is to model how they mentally transform informational inputs into ideas and actions. Yet, the issue with Turing's mind as a machine metaphor, is that it eschews the very thing that it purports to model: the human — mathematician or entrepreneur-in the flesh, along with her eyes, ears and hands, and beyond her own brain and body, the physical sphere within which she is situated while she processes information, including her notepads filled with scribbled ideas, drawings, strikeouts, and possibly the social sphere which she can probe while she is cognising: 
her peers, mentors, and so on (Hutchins, 1995; Vallée-Tourangeau and Vallée-Tourangeau, 2014). In this paper, we introduce a different theoretical framework, the SysTM or systemic thinking model and discuss how it could inform future work on entrepreneurial cognition.

A core but implicit assumption of the CIP model is illustrated by the doctrine of methodological individualism (Weber, 1978), according to which intentions are the necessary antecedents and motors of behaviour. This assumption imposes an implicit hierarchy where thoughts must precede action (Knappett, 2005). The methodological individualism postulate is also prevalent in work on entrepreneurial cognition: to seek to understand how personality and intentions ultimately predict entrepreneurial activity (e.g., Verheul et al., 2012) is to assume implicitly that the individual entrepreneur is the ontological locus of entrepreneurship, and that entrepreneurship success must be a direct consequence of the entrepreneur's cognitive capacity, ability, and personality. An unfortunate corollary of the methodological individualism assumption is the tendency to study entrepreneurial cognition in settings where individuals are typically placed in a passive information acquisition role. Implicitly assuming that thought precedes action, experimenters stay in control of the incoming stimuli and the participants are "presented with" or "exposed to" carefully chosen information, often presented on static information displays such as computer screen or printed documentation (e.g., see Kraus et al., 2016 for a review).

The researcher's control over the information presented to the research participant, however, precludes the potentially constitutive role of action and of the immediate environment in entrepreneurial thinking and deciding. Like the Turing's mathematician-machine, research participants are reduced to passive information processors. More crucially, methodological individualism imposes a deductive path of information processing: entrepreneurial cognition is 
implicitly modelled as arising from pathway where actions are deduced from the processing of a mental representation. In doing so, it precludes the possibility that the entrepreneurial activity may also arise or evolve inductively, by directly acting upon actions possibilities available in one's immediate environment without formalising explicit intentions.

To overcome the limitations of methodological individualism, we proposed to move away from the mind-as-machine metaphor and instead focus on the nexus between thoughts and actions, namely cognitive interactivity, which we defined as "the meshed network of reciprocal causations between an agent's mental processing and the transformative actions she applies to her immediate environment to achieve a cognitive result" (Vallée-Tourangeau and ValléeTourangeau, 2017, p. 140). Figure 2 illustrates an alternative to the CIP model, namely the Systemic Thinking Model (SysTM), which conceives cognition as an emergent property in a complex system that includes, but cannot be fully specified by, mental processes (ValléeTourangeau et al., 2015; Vallée-Tourangeau and Vallée-Tourangeau, 2017).

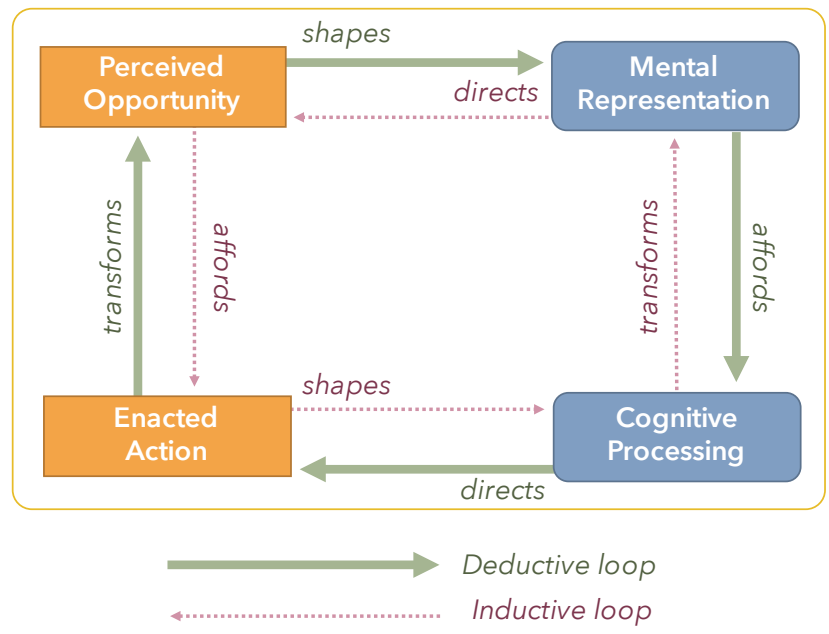

Figure 2. Systemic Thinking Model of Entrepreneurial Cognition

As Figure 2 shows, focussing on cognitive interactivity in entrepreneurship means recognising that entrepreneurial activity emerges, not from cognitive processing of mental representation alone, but from the interweaving of mental processing and enacted actions. 
Entrepreneurs are typically more than Rodin's thinkers. They are thinking agents, situated in a systemic thinking sphere, where they are free to manipulate and fiddle with the information that is immediately available to them. Unlike the experimenter's materials, perceived opportunities in the real world do not avail themselves in immutable information displays. They are discovered and sometimes uncovered or even created through poking and understanding one's dynamic environment.

By considering cognition as an emergent property of a dynamic system where the entrepreneur is conceptualised with both her thoughts and actions interacting in situ, the SysTM offers new research avenues. First, by assuming entrepreneurial activities can arise through inductive cognitive processing (see Figure 2), one can hypothesise that entrepreneurship may also emerge through the - unplanned but transformative - actions an individual may undertake to physically transforms her immediate landscape of opportunities. One example that springs to mind might be attending a networking event without a clear purpose. Such unplanned but transformative actions may thereafter shaping her mental representation of the possible and afford new ways of processing information, resulting in a plan (or further unplanned actions). Whether this happens, that is, whether entrepreneurial activity may precede planning, remains to be tested. Second, the systemic thinking conceptual framework highlights the need to better understand the landscape of "perceivable affordances" (Norman, 2013) - that is the opportunities for actions that individuals are able to perceive in their environment—and whether people differ in (a) their ability to perceive affordances and (b) their propensity to act upon them even in the absence of an entrepreneurial intentions or plans. Third, the SysTM also highlights the need to better understand the landscape of "latent affordances" (Gibson, 1986), that is, the set of latent opportunities for action available in one's immediate environment. While the hyper-connectened 
modern world may be anyone's oyster, better understanding the latent opportunities for action that are actually available in any individual's immediate environment and the skills and competences required to act upon them may also bring the cognitive psychology of entrepreneurship forward. In other words, from the SysTM perspective, to understand entrepreneurial activity is not merely to understand what goes on in an entrepreneur's head. Rather, it is to understand how entrepreneurship emerges from the reciprocal influences of mental representations and processing, latent affordances in the environment, and enacted actions.

To conclude, this paper proposes an alternative theoretical perspective on the psychology of cognition in general, and the cognitive psychology of entrepreneurship in particular: the Systemic Thinking Model. As such, it is not antithetical to classical information processing models, which assume methodological individualism and conceive intentions as the necessary antecedent of entrepreneurial activity. Instead, it offers a synthetical framework to accommodate both classical and well-documented models such as the theory of planned behaviour (Ajzen, 1991) and new approaches suggesting that entrepreneurial action cannot be reduced to a deliberate cognitive process (Lerner et al., 2018; Wiklund et al., 2017). By instating and conceptualising the role of inductive mechanisms and affordances, the SysTM framework challenges the mythical view of entrepreneurs as visionary individuals who perceive opportunities, think carefully about what action to take, and then enact their thoughtful plan. Without discarding the possibility of intention-driven entrepreneurial actions through deductive processing, it posits affordance-driven actions through inductive processing as a plausible complementary driving force for entrepreneurship.

1482 words. 


\section{References}

Ajzen, I. (1991), “The theory of planned behavior”, Organizational Behavior and Human Decision Processes, Vol. 50 No. 2, pp. 179-211.

English Oxford Living Dictionaries. (n.d.). "Entrepreneur", available at:

https://en.oxforddictionaries.com/definition/entrepreneur (accessed 25 July 2018).

Fodor, J.A. (1981), “The Mind-Body Problem”, Scientific American, Vol. 244 No. 1, pp. 114 123.

Gibson, J.J. (1986), The Ecological Approach to Visual Perception, Erlbaum, Hillsdale, NJ. (Original work published 1979).

Hutchins, E. (1995), Cognition in the Wild, MIT Press, Cambridge, Mass.

Knappett, C. (2005), Thinking through Material Culture: An Interdisciplinary Perspective, University of Pennsylvania Press, Philadelphia.

Kraus, S., Meier, F. and Niemand, T. (2016), "Experimental methods in entrepreneurship research: the status quo", International Journal of Entrepreneurial Behavior \& Research, Vol. 22 No. 6, pp. 958-983.

Krueger, N.F. (2005), “The Cognitive Psychology of Entrepreneurship”, in Acs, Z.J. and Audretsch, D.B. (Eds.), Handbook of Entrepreneurship Research, Vol. 1, SpringerVerlag, New York, pp. 105-140.

Lerner, D.A., Hatak, I. and Rauch, A. (2018), “Deep roots? Behavioral Inhibition and Behavioral Activation System (BIS/BAS) sensitivity and entrepreneurship", Journal of Business Venturing Insights, Vol. 9, pp. 107-115.

Norman, D.A. (2013), The Design of Everyday Things, 2nd Ed., Basic Books, New York. 
Stevenson, H.H. and Jarillo, J.C. (1990), “A Paradigm of Entrepreneurship: Entrepreneurial Management”, Strategic Management Journal, Vol. 11, pp. 17-27.

Sun, R. (Ed.). (2008), The Cambridge Handbook of Computational Psychology, Cambridge University Press, Cambridge.

Turing, A.M. (1936), “On computable numbers, with an application to the Entscheidungsproblem", Proceedings of the London Mathematical Society, Vol. 42 No. 2, pp. $230-265$.

Vallée-Tourangeau, G., Abadie, M. and Vallée-Tourangeau, F. (2015), “Interactivity fosters Bayesian reasoning without instruction.”, Journal of Experimental Psychology: General, Vol. 144 No. 3, pp. 581-603.

Vallée-Tourangeau, G. and Vallée-Tourangeau, F. (2014), “The spatio-temporal dynamics of systemic thinking”, Cybernetics \& Human Knowing, Vol. 21 No. 1-2, pp. 113-127.

Vallée-Tourangeau, G. and Vallée-Tourangeau, F. (2017), “Cognition Beyond the Classical Information Processing Model: Cognitive Interactivity and the Systemic Thinking Model (SysTM)", in Cowley, S.J. and Vallée-Tourangeau, F. (Eds.), Cognition Beyond the Brain, 2nd Ed., Springer, Cham, Switerland, pp. 133-154.

Verheul, I., Thurik, R., Grilo, I. and van der Zwan, P. (2012), “Explaining preferences and actual involvement in self-employment: Gender and the entrepreneurial personality", Journal of Economic Psychology, Vol. 33 No. 2, pp. 325-341.

Weber, M. (1978), Economy and Society: An Outline of Interpretive Sociology, University of California Press. (Original work published 1922), Berkeley.

Wiklund, J., Yu, W., Tucker, R. and Marino, L.D. (2017), “ADHD, impulsivity and entrepreneurship", Journal of Business Venturing, Vol. 32 No. 6, pp. 627-656. 